\title{
Estimation of solar energy on vertical 3D building walls on city quarter scale
}

\author{
F. Jaugsch ${ }^{\mathrm{a}} *$ M.-O. Löwner ${ }^{\mathrm{a}}$
}

${ }^{a}$ Institute for Geodesy and Photogrammetry, Technische Universität Braunschweig, Germany - (f.jaugsch, m-o.loewner)@ tu-bs.de

\section{Commission VI, WG VI/4}

KEY WORDS: Urban photovoltaic potential, vertical walls, renewable energy, 3D building model

\begin{abstract}
:
In urban areas, solar energy is one promising source of renewable energy to achieve the EU parliament's goal of reducing $\mathrm{CO} 2$ emissions by $20 \%$ compared to 1990 . Although annual radiation on vertical walls is lower than that on roof surfaces, they are larger in area and, therefore may contribute to energy production. On the other hand, the modelling of shadowing effects is cost intensive in an complex urban environment. Here we present a method for the calculation of solar potential on vertical walls for simple 2D maps with additional building height information. We introduced observer point columns that enable a fast decision whether a whole vertical set of observer points is illuminated or not. By the introduction of a maximum shade length, we reduce processing time in ArcGIS. 206,291 points of 130 buildings have been analysed in time steps of 15 minutes resulting in 15,769 pairs of solar angles. Results disprove the potential of vertical walls serving to fill the winter gap of roof mounted solar energy plants. Best wall orientation for the deployment of solar panels are west and east in summer, whereas it is southeast in winter.
\end{abstract}

\footnotetext{
* Corresponding author
} 


\section{INTRODUCTION}

Solar energy plays an important rule performing the energy revolution in Germany and promoting renewable energy at all. In 2013, 29.7 TWh have been earned in Germany covering the energy need of about 8.5 million households (Bundesverband Solarwirtschaft, 2014). Thereby decentralized yield of solar potential, especially in urbanized areas, plays an even more important role, because energy demand at cities is high and transportation routes are short. This in particular accounts for the fact that in Europe 40-45 \% of energy consumption is attributed to urban households (Catalina et al., 2013). This numbers will increase due to ongoing urbanization.

To achieve the goal of reducing $\mathrm{CO} 2$ emissions by $20 \%$ compared to 1990 the EU parliament published the directive on the energy performance of buildings (European Parliament, 2010). This directive calls for new buildings from 2020 to be nearly zero energy buildings. Following the described general framework for the calculation of energy performance of buildings, insulation, passive and active solar heat gain have to be considered, next to active solar devices for the production of electrical power. That means that also heat gains by window areas are of importance as well as reduced heat loss due to smaller temperature gradients on insulated walls.

Until today, most of the active solar systems, either thermal or photovoltaic devices, are mounted on south oriented roof surfaces with an inclination of about 30 degrees. Due to decreasing global solar irradiance and decreasing vertical inclination of the sun, power production decreases in winter, even on optimized panels. As a solution, vertical walls could be equipped. They show better angles to incoming sunlight in winter and, therefore, act as a compensation in addition with roof-mounted energy or heat plants.

Estimations of solar potential on roofs have been studied for about 20 years (Wittmann et al., 1996, Gadsdena et al., 2003, Nguyen and Pearce, 2012). Tilted roofs generally found suitable for the production of electrical power and domestic hot water. However, calculating solar potential of vertical wall surfaces are comparable rare in comparison to roof-related estimations.

Nevertheless, Redweik et al. (2013) stated that even though annual radiation on vertical walls was lower than that of roof surfaces, façades could contribute to the production of energy, because they but are larger in area.

In general, global solar radiation can be divided into three components. These are direct, diffuse and reflected radiation. Global radiation is maximal when the sky is cloudless and dry and, therefore, less radiation is absorbed or reflected by the atmosphere. Since reflection values are only assessable by very cost intensive calculations, they are almost neglected in the field of solar energy estimation. Diffuse radiation, however, needs long-term empirical data to be incorporated.

On the ground and especially in an urban environment, shadowing effects are the most important reasons for the reduction of solar radiation on vertical walls. They origin from neighboring buildings or from other obstacles like trees or city furniture. Cheng et al. (2006) found a correlation between form and density on the one side and solar potential on roofs and walls on the other side by applying a sky view factor However, effects differed for either roofs or walls. Even small obstracles on roofs, i.e. dormers or chimneys, cause loss on solar potential by at least $10 \%$ (Ben Fekih Fradj and Löwner, 2012).

Input data plays an important rule for the modelling of solar potentials of vertical walls. Since Digital Situation Models based on LIDAR seem to be sufficient (e.g. Jacubiec and Reihard, 2013, Lukač et al., 2013) for the analysis of roof structures, vector based 3D models become more relevant.
Especially CityGML (Gröger et al., 2012) as an Open Geospatial Consortium Standard has been applied to calculate solar potential (e.g. Baumanns and Löwner, 2009, Eicker et al., 2014) for either calculation solar potential on roofs or walls. For the application of semantical enriched city models for the estimation of solar potential, reference is made to Biljecki et al. (2015). However, public authorities, especially in smaller cities still use 2D maps with additional information about building heights. Hence, tools for the estimation of solar potential based on simple data input is desirable.

Here we present a method for the calculation of solar potential on vertical walls implemented in ArcGIS that requires 2D maps with additional height information. Since ArcGIS seems still to be the most used software for public authorities, tools for this software suite are required. However, already build in tools like the solar radiation tool need a fine grained DTM as a data input. Simple 2D map representations with additional height information are not supported.

Starting from imaginary 3D blocks models (LoD1) derived from shape files with additional height information, we introduced observer point columns that enable a fast decision on whether a whole vertical set of observer points is illuminated or not. By the introduction of the maximum shade length, we reduce processing time. To get access to the ArcGIS functionality and to create a tool that is independent of further software, we used ArcPy. We apply the algorithm to a city quarter of Braunschweig, Lower Saxony.

In the next section, we give a brief overview over the state of the art. Our workflow for the calculation of irradiance including the generation of observer points, the testing for shading and the calculation of incoming energy from the sun is documented in section 3. In section 4 , we present our results based on two different simulation scenarios for the global solar irradiance. We present the annual cycle of solar radiation, radiant power values of vertical walls with different orientation and look for the ratio of energy production in relation to height of observer points. We end up with a discussion.

\section{STATE OF THE ART FOR THE CALCULATION OF SOALR POTENTIAL ON VERTICAL WALLS}

Here, we give a short overview on work that is directly related to the problem of the identification of shaded wall surfaces. A full review of solar potential modelling approaches can be found in (Freitas et al., 2015).

In a first approach, Scartezzini et al. (2002) used cost intensive ray tracing simulation techniques to identify the spatial distribution of solar radiation and daylight fluxes over building façades and roofs regarding active and passive solar energy.

Redweik et al. (2013) used a LIDAR derived digital surface model (DSM) to estimate solar potential on roofs and façades in an urban environment. To overcome the problems of a $2.5 \mathrm{D}$ tessellation, they created a raster based façade map by identifying vertical building parts by the definition of a threshold of 72 degrees in slope. Resulting wall elements reveal the same spatial extend as the DSM resolution, i.e. $1 \mathrm{~m}$. For every hour of the year, Redweik et al. (2013) calculated a shadow map and a façade shadow map. The algorithm is raster based and follows the solar geometry described in (ASTALM, 2011). As input, the DSM as well the façade map is needed. While every cell of the DSM is touched for the evaluation of shadow effects on façades, a feature based pre-analysis of neighboring buildings is not included.

Catita et al. (2014) extend the above describe approach by the introduction of "hyperpoints", i.e. points having the same $\mathrm{x}$ any $\mathrm{y}$ coordinate but different $\mathrm{z}$ values. The resulting raster representation of vertical walls are further used to map them to 
CityGML and overlaid with manually modelled 3D buildings. As a result, every point at any façade can be analyzed concerning solar earnings.

Hofierka and Zlocha (2012) extend the raster based solar radiation model r.sun (Š́ri and Hofierka, 2004) for the application for 3D City models to cover the assessment of solar potentials of vertical surfaces. They use a combined vectorvoxel approach to disaggregate vector based box models of buildings. After the segmentation of the original 3D polygons to smaller elements that are suitable for the shading calculation, each of these polygons is represented by a unique voxel. In the next step, solar geometry parameters, i.e. normal vector and $n$ vectors defining a solar ray direction are calculated. However, the size of $n$ is not discussed, although it is directly related to the temporal resolution of the solar model, i.e. the time intervals used to model shading effects and, thus, the incoming solar energy. Further, Hofierka and Zlocha (2012) calculate solar geometry parameters for all voxels without prior ascertainment of neighboring buildings. This is remarkable since this step is highly cost intensive.

Wieland et al. (2015) published a method for the calculation of solar irradiance on roofs and façades using CityGML (Gröger et al., 2012) as input data. After dividing all surfaces, i.e. roofs and façades into equal-sized raster cells, direction vectors to the particular sun position are calculated for all these cells. For all these vectors the the PostGIS "ST 3DIntersects" is applied to evaluate whether the cell is insulated for the respective time step. For all time steps direct and indirect radiation is calculated according to (Š́ri and Hofierka, 2004). However, timeconsuming calculation of clouding again is performed without consideration of adjacent obstacles.

\section{WORKFLOW FOR THE CALCULATION OF IRRADIANCE}

Here, calculation of irradiance on a vertical wall is divided into four steps. First, the position of the sun is calculated. Since this step results in angle pairs for discrete daytimes, this step determines the temporal resolution of the model. Second, observer points at the vertical walls have to be created. Observer points are used to disaggregate the wall surface and, therefore, determine the spatial resolution of the model. Third, direct visibility of the sun has to be verified for every observer point and for every time step. This step is the most cost intensive on, because number of computation steps results from temporal resolution multiplied with the spatial resolution. Therfore it needs to be optimized.

In a last step, radiation has to be calculated for every observer point if not shadowed at the certain time step. At this point model results vary from input data, e.g. the solar irradiance, omission of indirect or diffuse radiation and formulas for the calculation of irradiance for surfaces with non-horizontal orientation.

The overall workflow to calculate the first and second part is depicted in Figure 1 and explained in the following text.

\subsection{Calculation of the sun's position}

The main framework for the modelling of the energy received by radiation is given by the position of the sun calculated for a certain temporal resolution. Sun position was represented as azimuthal and elevation angels after (ASTALM 2004; Meeus 2000) every fifteen minutes using Perl. Sun data was stored in a simple data table. Pairs of solar angles that have an elevation angle smaller than 5 degrees did not enter the data table (rf. Richter and Löwner, 2011; Jaugsch et al., 2014). Overall,
15,769 pairs of solar angles have been calculated. Calculation, of cause, is made for a location representing the research region.

\subsection{Generation of observer points}

Observer points are deployed on the vertical walls in a regular grid. However, for visualisation reasons, $\mathrm{x}$ and $\mathrm{y}$ coordinates of the observer points were not determined directly from the walls but on a $0.5 \mathrm{~m}$ buffer. In contrast to Lu et al. (in press) we did not use the ArcGIS Multipatch file format but stored the 3D coordinates in an extra attribute table to have easy access and to reduce complexity for the user.

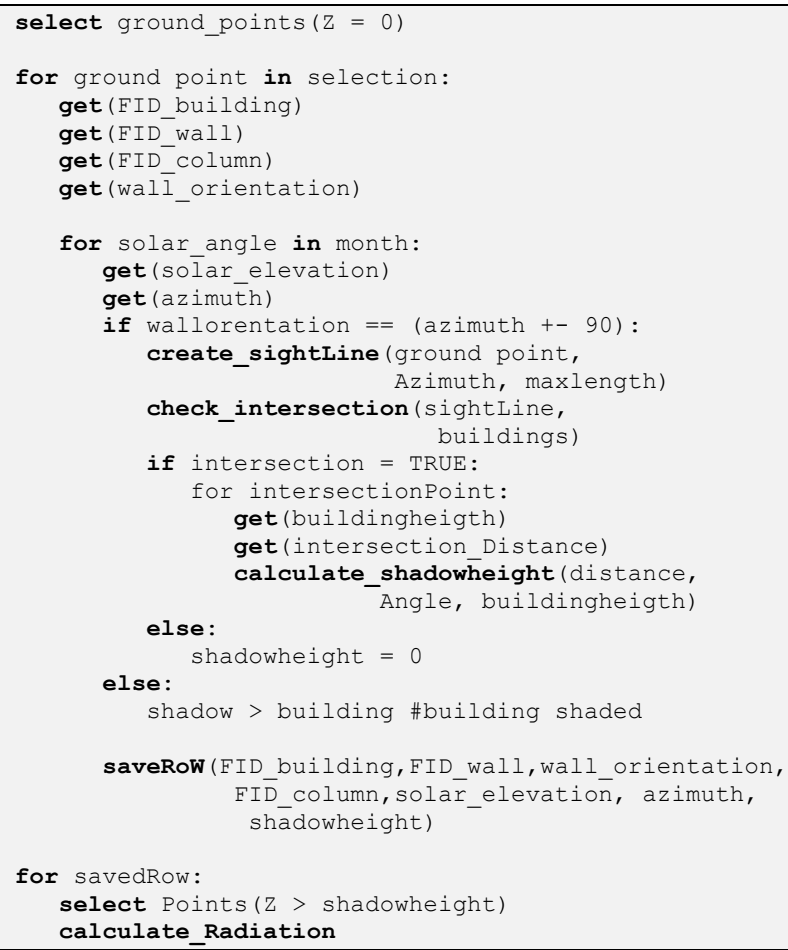

Figure 1. Pseudocode for the determination of radiation time and angle for single observer points.

Starting from the ground points, horizontal resolution was used to determine the $\mathrm{z}$ coordinates. Points of equal $\mathrm{x}$ and $\mathrm{y}$ coordinate were arranged in an array, called point column (Figure 2).

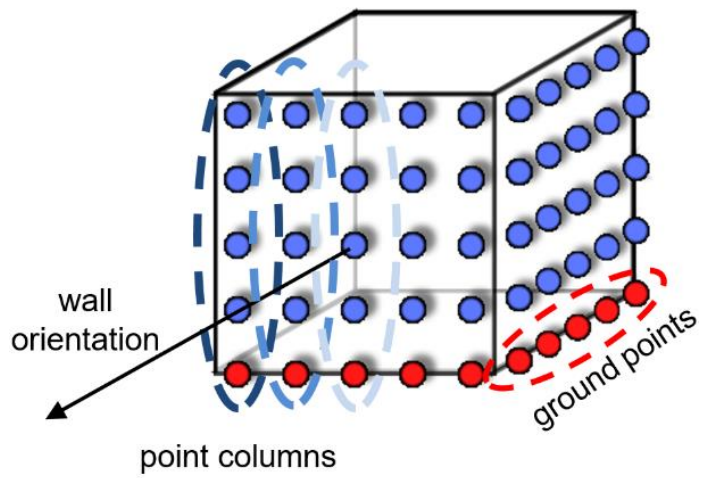

Figure 2: Observer points organized in ground points with $\mathrm{z}=0$ and associated point columns. Corresponding wall orientation is stored together with the point columns.

The introduction of point columns is a crucial step toward processing efficiency. In the simplest case, all other points in 
the point column are tagged as insulated without further processing if the ground point is determined to be insulated. The same accounts for all points above an insulated observer point, even if the ground point is shaded. Deployment of observer points for the investigated city quarter is depicted in Figure 3.

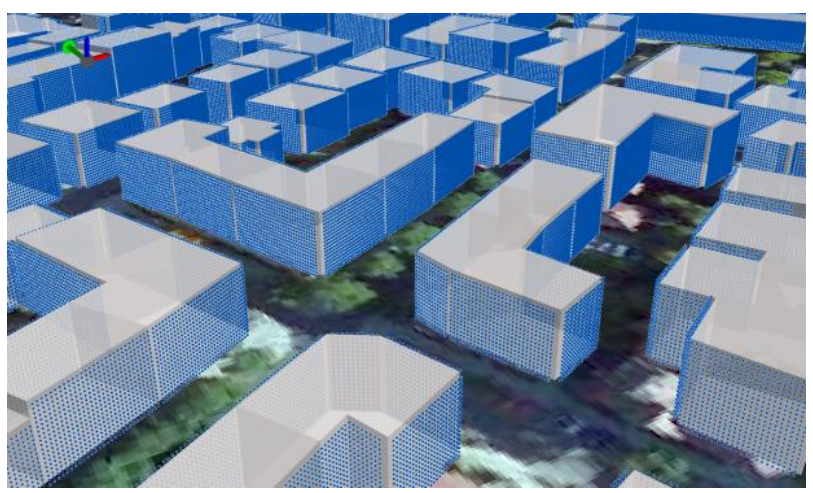

Figure 3. Observer points generated and visualized for the investigated city quarter (green arrow indicates north). Here, a regular grid of $1 \mathrm{~m}$ resolution was created.

In addition to observer point generation and their organisation as point columns, horizontal wall orientation was calculated and stored accordingly. Since no incline walls are regarded calculation of a vertical component is not required.

\subsection{Testing for shading}

For each time step, i.e. for each pair of solar angles, maximum shading line was calculated from the sun's elevation angle at the give time step and the building height of the tallest building of the investigated city quarter. The result is the maximal possible shadow line at the given time step represented as a distance on a horizontal plane. Taken the tallest building for the whole research area is feasible, since buildings are quite similar. For larger study areas, buffer operations are recommended.

Further, for each ground point a line was created with the length of the maximum shading line, the ground point itself and the azimuthal angel at the given time step. All those buildings intersecting that line, if at all, were identified and stored in a temporary set. If the temporary set is empty, no building lies within the range of the maximum shading line and the particular ground point is insulated. Hence, because only buildings are considered as possible obstacles, all the other points in the specific point column are insulated, too. They do not have to be considered any more.

If the set is not empty, i.e. if a building lies within the range of the maximum shading line, shading of this point and further members of the specific point column is at least possible. Therefore, for each building in the set shadow height at the $\mathrm{x}, \mathrm{y}$ position of the ground point is calculated after (1) and (2).

$$
\begin{gathered}
h_{s}=\Delta d * \tan (\alpha) \\
\Delta d=\frac{h_{b}}{\tan (\alpha)}-d_{b}
\end{gathered}
$$

with

$$
\begin{aligned}
h_{s} & =\text { shadow height } \\
h_{b} & =\text { building height } \\
d_{b} & =\text { distance point-building } \\
\alpha & =\text { sun elevation angle }
\end{aligned}
$$

\subsection{Calculating accumulated irradiance}

Now, for each time step and each ground point conditions on shadowing are available. The next step is to calculate the accumulated received energy for all the points over different time spans.

Therefore, the attribute table was searched applying a SQL statement to get all the points of a certain point column and mark those, which are above the calculated shadow height. This is, because those points are insulated at the certain time step, i.e. for 15 minutes.

In general, this incoming solar radiation is described as solar irradiance $\left[\mathrm{W} / \mathrm{m}^{2}\right]$. Values refer to horizontal surfaces and cannot directly be use for energy estimation, neither for inclined surfaces nor for vertical walls. Further, global solar irradiance is composed of direct radiation, indirect radiation and, for inclined surfaces, reflection from other surfaces.

Here, only direct radiation $\left(I_{d}\right)$ after (Gassel, 1997) entered the modelling results. Calculation was conducted following the formulas (3) and (4). However, diffuse radiation could be added easily, whereas reflection needs further geometrical analysis. Radiation numbers were cumulated on a monthly basis.

$$
\begin{gathered}
I_{d}=I * \frac{\sin \theta}{\sin \alpha} ; \\
\sin \theta=\sin \alpha * \cos \beta+\cos \alpha * \cos \left(\gamma_{s}-\gamma\right) * \sin \beta
\end{gathered}
$$

with

$$
\begin{aligned}
& I_{d}=\text { Direct radiation on tilted surface } \\
& I=\text { Direct part of solar irradiance } \\
& \mu=\text { Radiation angle on tilted surface } \\
& \beta=\text { Surface slope }\left(\text { vertical }=90^{\circ}\right) \\
& \gamma_{s}=\text { Surface orientation }\left(\text { south }=0^{\circ} ; \text { west }=+90^{\circ}\right. \text { ) } \\
& \gamma=\text { Sun azimuth angle }
\end{aligned}
$$

\section{RESULTS}

\subsection{Simulation scenarios and technical setup}

Model results vary from input data, especially from the solar irradiance. This value is a measured one and available through publication of different sources for different temporal resolution. Measured values aggregate direct radiation, indirect radiation and reflection from other surfaces. However, calculating indirect radiation and reflection on vertical walls would require additional formulas than depicted in (3) and (4).

Diffuse radiation plays a big role in the overall radiation term but has not been calculated for the following reason. Diffuse radiation is the result of a complex interaction of cloud cover and vapor content of the lower atmosphere. However, cloud cover data is hardly to assess. It varies from day to day, if not during a day and, therefore, averages are hard to calculate. The same accounts for the vapor content and aerosols, which even depend on traffic intensity, wind speed and urban morphology (Ghassoun et al., 2015).

We applied two different approximations for the estimation of irradiance on the observer points for different time scales, i.e. for a whole year and for a monthly basis. In Germany the ratio of direct to diffuse radiation is about 40 to 60 and an annual mean of global solar irradiance of $135 \mathrm{~W} / \mathrm{m}^{2}$. Therefore, we assumed $55 \mathrm{~W} / \mathrm{m}^{2}$ for each calculation step in average.

To simulate the course of radiation values in the most realistic manner, long-term average of single months for global solar 
irradiance and its direct proportion has been assumed. In both cases, data was taken from open data portal of the Deutscher Wetterdienst (German Weather Service, 2016). Values the calculation is based on are depicted in Figure 4.

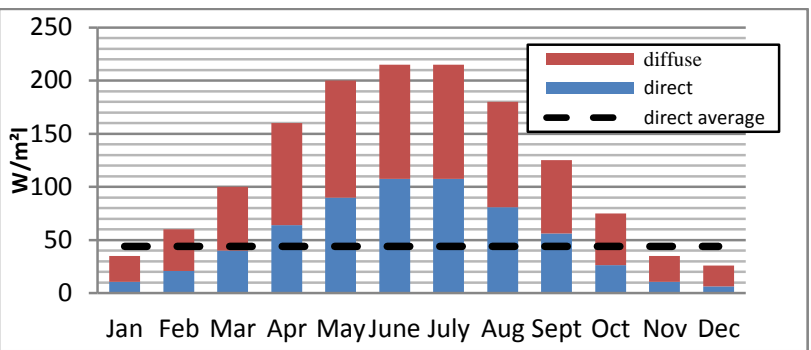

Figure 4: Monthly solar irradiance (direct/diffuse) together with the annual average serving as input data for (3) and (4) (source DWD, rf. Palz and Greif, 1996).

The method was implemented on an ArcGIS environment using the well-known ArcPy package. Calculations were performed on different computers ranging from outdated to state of the art, e.g. Intel Core i7 CPU@3.50GHz, 8 GB RAM, SSD-Drive.

14,566 single steps needed to be calculated for a representative building of a height of $20 \mathrm{~m}$ and a wall surface of $2,457 \mathrm{~m}^{2}$. Using the state of the art computer, calculation of such a building took 40 seconds for the calculation of shading effects. However, writing the data applying an update courser needed
111 seconds resulting in approx. 2.5 minutes for a building per month.

130 buildings entered the model with an average high of $16 \mathrm{~m}$ and a total wall surface of $206,291 \mathrm{~m}^{2}$. Buildings are of representative shape and size for Braunschweig (253,000 inhabitants, second largest city of Lower Saxony, Germany covering an area of $192.1 \mathrm{~km}^{2}$ with a population density of 1,293 inhabitants per $\mathrm{km}^{2}$ ).

\subsection{Annual cycle of solar radiation on vertical walls}

Annual cycle of solar radiation on vertical walls is depicted in Figure 5. No distinction was made between orientations of the wall surfaces. However, we entered the annual averaged solar irradiance (depicted as greyish bars) and compared this with the monthly averaged values taken from DWD. A clear difference can be observed concerning the course of the year. Since modelling results calculated from the annual averaged input data stays almost constant, a clear trend can be observed for the monthly averaged input data. Latter reveals a peak in July with $4,525,736 \mathrm{KWh}$ for all investigated buildings. Winter months show smaller values disproving the assumption that solar radiation on vertical walls could close the energy gap resulting from lower earnings of roof mounted solar panels.

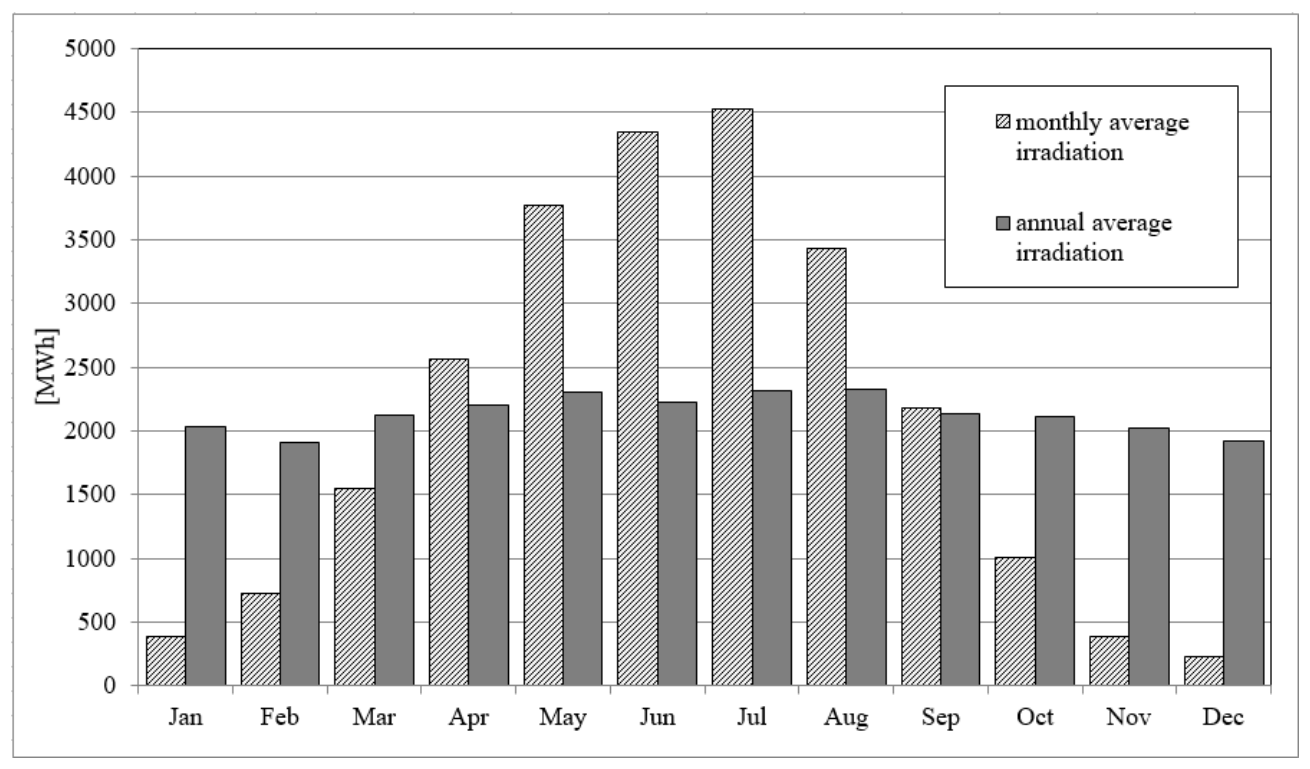

Figure 5. Annual cycle of solar radiation on vertical walls of 130 buildings in the research area. Greyish bars result from annual averaged radiation input values, dashed bars from monthly averaged input values (from German Weather Service, 2016). Values accumulate from all wall surfaces without a distinction of orientation.

\subsection{Values of radiant power for vertical walls with different orientation}

Radiant power values of vertical walls have to be differentiated concerning their orientation. 


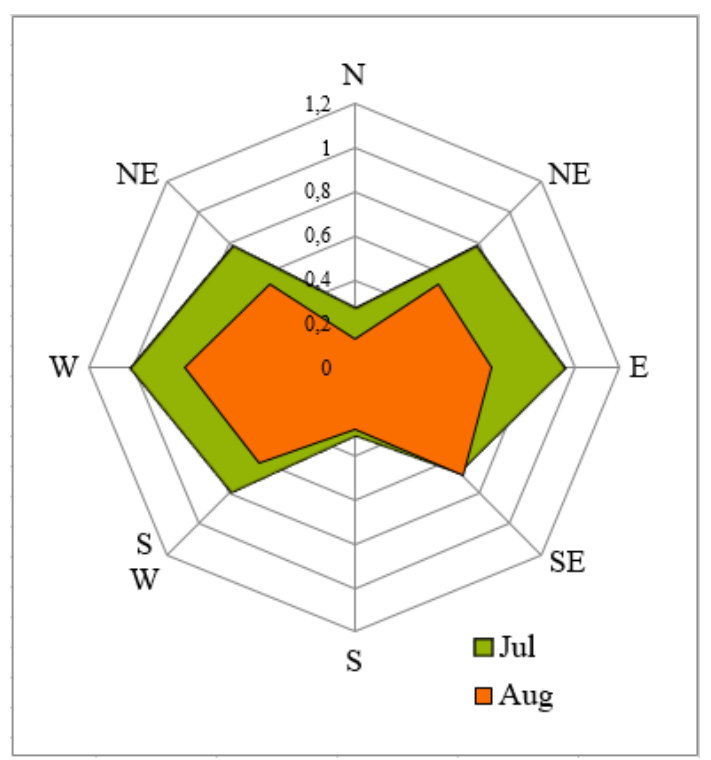

Figure 6. Radar chart of averaged daily-received energy for walls with different orientation $\left[\mathrm{kWh} / \mathrm{m}^{2}\right]$ for July and August.

Solar radiation on vertical walls is expected to be different, because of orientation. Since elevation angle of the sun is low in early daytimes and at the evening, angle if impact on vertical walls is advantageous for walls facing to the west and to the east. South oriented walls, however, are estimated to have relatively small energy value, because of high elevation level. Again, differences in modelling results may result from input data, especially the solar irradiance averaged over different time spans.

For summertime the average daily-received energy for walls with different orientation for July and August are depicted in Figure 6 as a radar chart. Input data is the global solar irradiance on a monthly average. It is evident that west and east facing walls receive the most energy with about $1 \mathrm{kWh} / \mathrm{m}^{2}$ in July and about $0.6 \mathrm{~kW}$ per hour in August. South facing walls just receive up to 0.3 and $0.2 \mathrm{~kW}$ per hour, respectively. Since roof mounted solar panels are best performing when facing to the south, our results show that panels mounted on west and east facing vertical walls could close the energy gap in early and late daytime on a diurnal timescale.

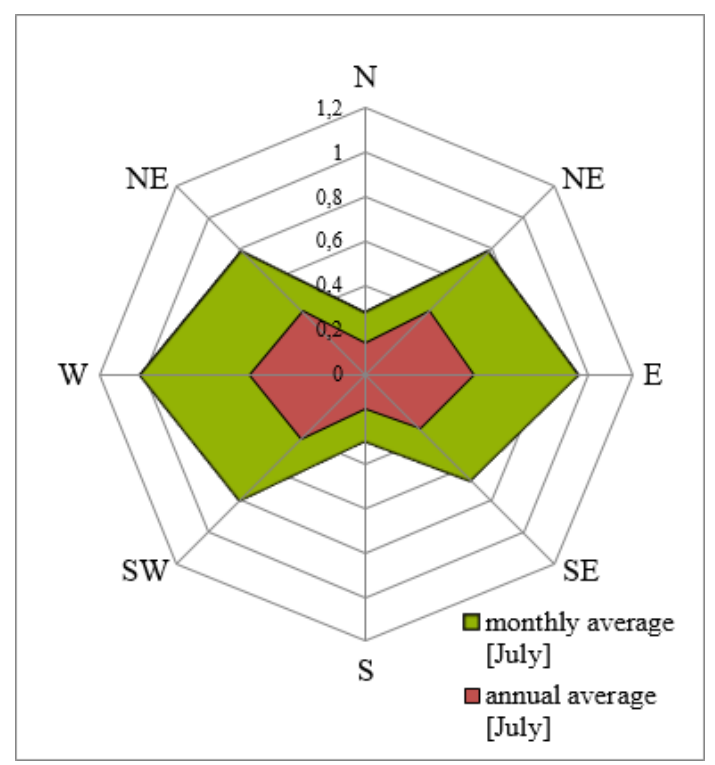

Figure 7. Variation of modelling results of averaged dailyreceived energy for walls with different orientation $\left[\mathrm{kWh} / \mathrm{m}^{2}\right]$ depending on input data for July.

However, monthly analysis is strictly related to time resolution of input data. Figure 7 explains the differences between annual averaged solar irradiance and monthly averaged solar irradiance. Because solar irradiance is higher in summer if viewed on a monthly basis (rf. Figure 4), modelling results will reflect this fact.

Although our studies already proved that the energy winter gap cannot be levelled out the energy gap resulting from lower earnings of roof mounted solar panels best performing vertical walls are still of interest. Because solar earnings are decreasing in winter times while energy demand is increasing, optimal deployment of solar panels should be aimed at.

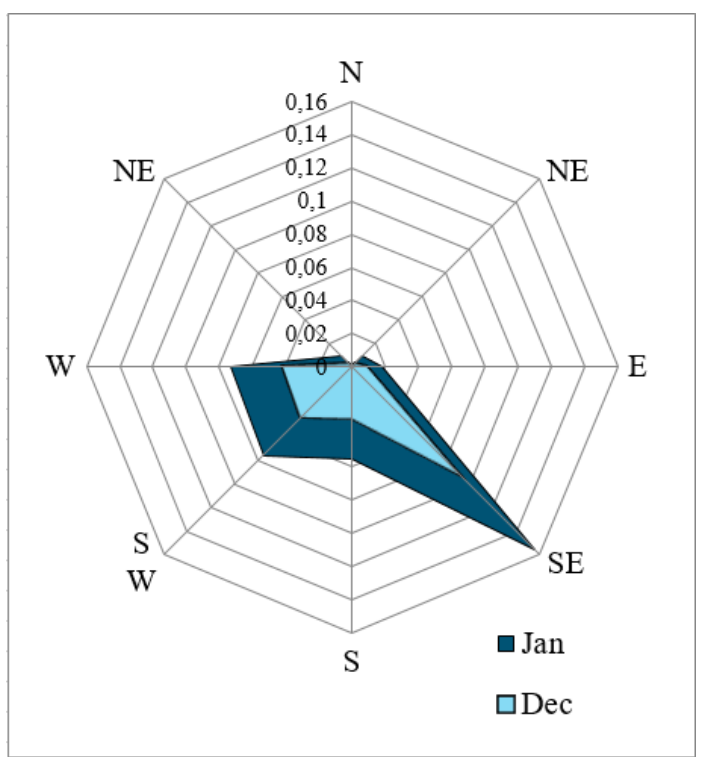

Figure 8. Radar chart of averaged daily-received energy for walls with different orientation $\left[\mathrm{kWh} / \mathrm{m}^{2}\right]$ for December and January.

Figure 8 depicts the differences in energy received from differently orientated vertical walls in winter (December and January). One can see that, first, the amount of energy is one dimension smaller than energy received in summer and, second that southeast-orientated walls are the best performers. Because days are significantly shorter in central Europe sun rises not in the East but in South east. Sunset in West may be explained by daylight-saving time in Germany. On the other hand, asymmetry of the diagram may also be explained by specific urban morphology in the research area. For urban planning purposes, this will be of interest for ongoing studies to evaluate optimized urban structure for solar energy production.

\subsection{Ration of energy production in relation to height of observer points}

The amount of solar energy is not only differentiated by orientation of vertical walls but on single walls, also. Figure 9 indicate the differentiation of solar radiation received in summer. Differences of observer points at one wall are caused by shadowing effects. It is apparent, that shadowing effects are getting smaller the higher an observer point is placed. Thus, energy earning is higher for high-lying observer points. Since low-lying observer points are expected to be shadowed more 
than high-lying ones the question arises which averaged height can be viewed as the best for the deployment of solar panels.

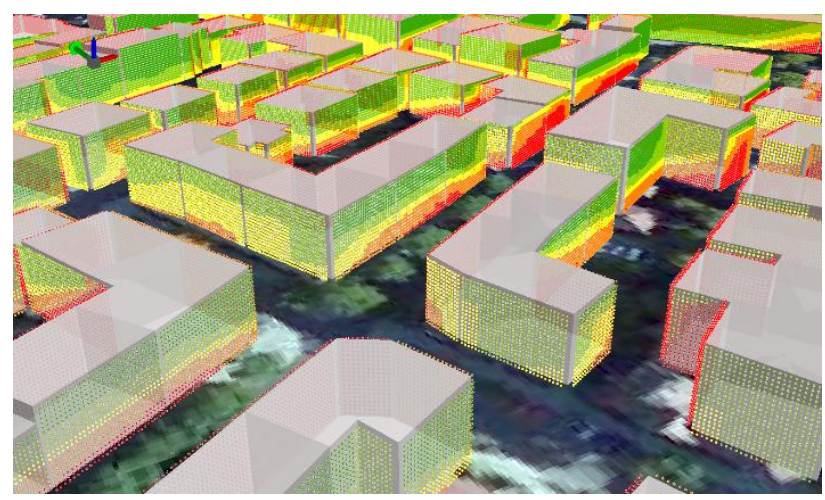

Figure 9. Differentiation of solar energy received on vertical walls during summer. Green observer points indicate insulation, red ones shadowing.

Percentage distribution of energy receipt related to altitudinal layers of observer points is depicted in Figure 10 for all orientations in July. The red line indicates the percentage distribution of east facing observer points related to the respective altitude.

Greyish bars and the red line intersect at an altitude of 12 meters. This indicates that the deployment of solar panels are more effective at this height and upwards. The highest energy receipt of $6.83 \%$ can be observed at the 16 meter level where $4.87 \%$ of the observer points are placed. However, it cannot be proved that this directly corresponds to the average of building heights in the research area, which is also 16 meters. To investigate such an interrelationship a representative number of investigation sites should be regarded.

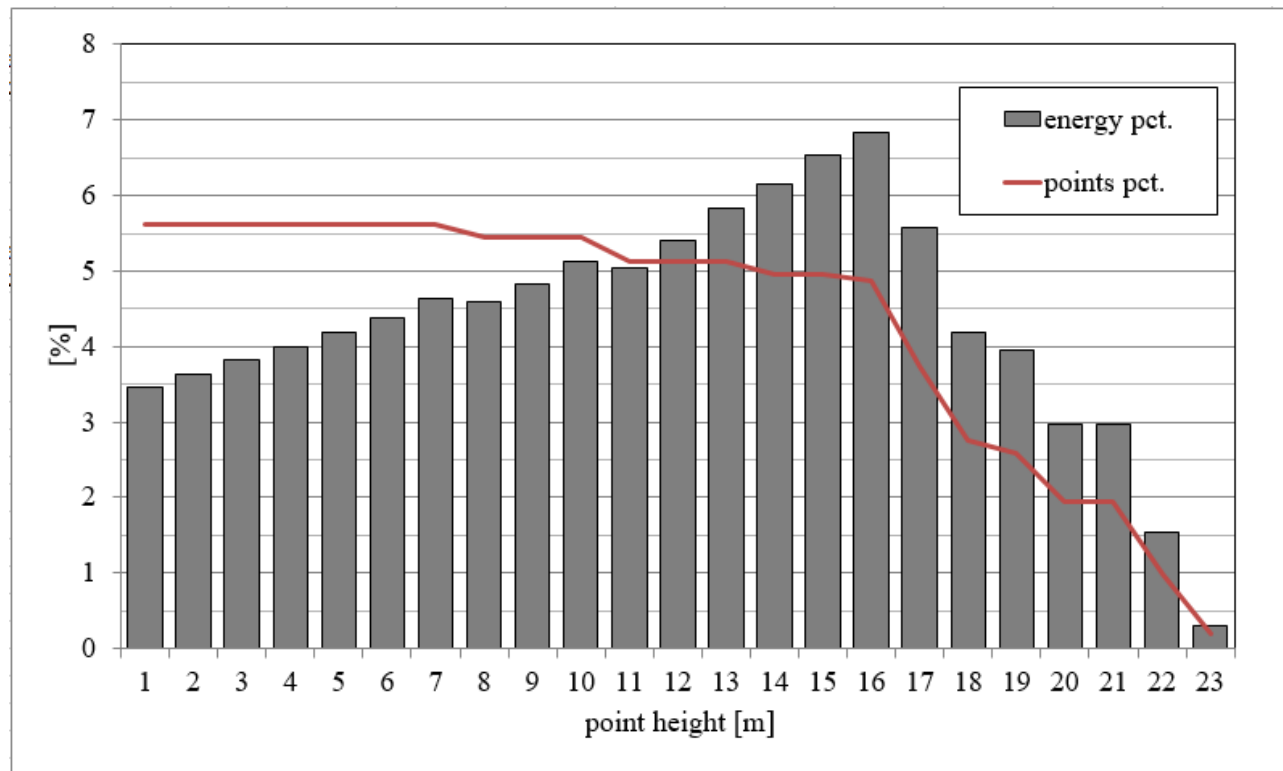

Figure 10. Percentage of energy production modelled for observer points of different heights (grey bars) on east facing walls in July. The red line indicates the percentage of points.

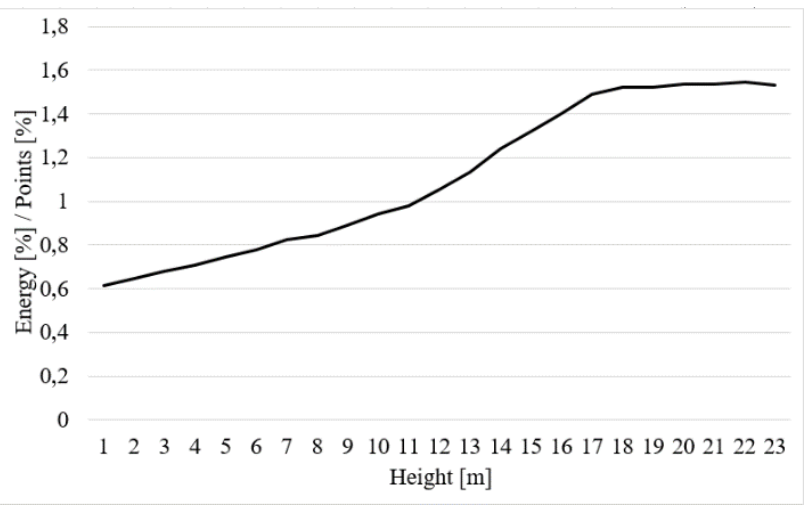

Figure 11. Ratio of percentage energy receipt to the percentage distribution of observer points of different height levels for the data of Figure 10.

Ratio of percentage energy receipt to the percentage distribution of observer points of different height levels is depicted in Figure 11. Calculations are based on data of Figure 10. As a ratio of one indicates, that the same proportion of available area is needed for energy production of the same proportion that is produced. An index of greater than one indicate a more effective placement. This is given at a height level of $12 \mathrm{~m}$ in the investigated area. Best proportion of 1.54 can be observes at 22 meters.

\section{DISCUSSION}

Here, we presented an estimation of solar energy on vertical walls on city quarter scale. We analyzed 130 buildings represented as blocks models created from ground surfaces and extruded with building measured heights. Observer points on wall surfaces were generated starting from ground points and were organized in point columns. Solar irradiance was modelled for every observer point for a 15 minutes time resolution starting with the maximum shading line representing the tallest building in the investigated city quarter.

Simple 2D maps with additional height information have been used as input data in an generally available GI software. However, using simple input data restricts the possibility to disaggregate building walls for considering window surfaces. 
The introduction of a point column coupled with the analysis of the maximum shading line for a given time, i.e. the position of the sun, is expected to be a fair trade of computing time an implementation effort. However, we only regarded buildings in our study. If tall trees come into play, the assumption that all observer points are illuminated if the ground point is not shadowed may be misleading. If big trees are in close vicinity of the building's façade, the stem may not affect shading but the canopy.

Diffuse radiation in an important point when calculating incoming radiation on a vertical wall. In Germany it accounts for about the half of incoming radiation, even if a wall is shadowed. Especially in winter times, incorporation of diffuse radiation would raise the earnings calculated here. Further work is aimed at incorporating the diffuse radiation. However, since we optimized the algorithm to decide whether a point is shaded or not for direct radiation estimation, the algorithm itself does not need to be changed.

Modelling results were analyses to answer the following question: First, may solar energy production close the gap of roof topped solar earnings in winter times, second, what orientation is the best to deploy solar panels in either summer and winter times and finally, from which height deployment reveals increasing efficiency.

Energy earnings on vertical walls increase in summer. This is due to longer exposure to the sun causing a wider azimuthal angle. In addition, global solar irradiance is higher in summer. Results were obtained applying two modelling scenarios, first incorporating only direct radiation and, second, adding a fixed value to simulate indirect radiation

We proved that west-oriented and east-oriented walls are the best performers in summer, whereas it is the southeast orientation in winter times. More research has to be performed to answer the question whether results for winter are affected by urban morphology. Since sun is very low in winter, influence of the general orientation of street canyons may have a greater influence on shading.

Height levels have been investigated to answer the question from which height the deployment of solar panels might be more effective. Causal, higher levels are less shadowed and, therefore, receive more solar energy. For the research area we proofed that the coefficient of energy and points are over one at a height level of $12 \mathrm{~m}$ with the average building height of $16 \mathrm{~m}$. Energy earning calculations are low in comparison to a number of open online tools. However, since those tools are a black box, we cannot judge their implemented methods. Nevertheless, indirect radiation and diffuse radiation still have to be implemented in our method.

The method applied here is not valid to estimate real earnings, at this time. Because we only used blocks models, no information about windows entered the simulation. Since the representation of windows in 3D city models, e.g. CityGML (Gröger et al 2012) is linked to a very high Level of Detail, using ArcGIS is problematic. The introduction of more flexible Level of details (e.g. proposed by Benner et. al. 2013, Löwner et al., 2013) could be a solution. Further, other obstacles, like city furniture and trees have to be regarded. Since our building geometries are extrusions from ground surfaces, this extension will be the next step.

\section{REFERENCES}

ASTALM, 2004. The Astronomical Almanac for the Year 2006, The Stationery Office, London.
ASTALM, 2011. Astronomical Almanac for the Year 2011, 2010. US Government Printing Office, Washington. ISBN 978 0-7077-41031.

Baumanns, K. and Löwner, M.-O., 2009. Refined estimation of solar energy potential on roof areas using decision trees on CityGML-data. Geophysical Research Abstracts 11.

Ben Fekih Fradj, N. and Löwner, M.-O. (2012). Abschätzung des nutzbaren Dachflächenanteils für Solarenergie mit CityGML-Gebäudemodellen und Luftbildern. (Assesment of suitable roof surface for solar energy plants using CityGML and aerial images). Löwner, M.-O., Hillen, F., Wohlfahrt, R. (eds.). Geoinformatik 2012 "Mobilität und Umwelt". Konferenzband zur Tagung Geoinformatik 2012 vom 28.-30.03.2012, Braunschweig, pp.. 171-177.

Benner, J., Geiger, A., Gröger, G., Häfele, K.H., Löwner, M.O., 2013. Enhanced LoD Concepts for Virtual 3D City Models ISPRS Annals of the Photogrammetry, Remote Sensing and Spatial Information Sciences II-2/W1, pp 51-61.

Biljecki, F., Stoter, J., Ledoux, H., Zlatanova, S., Çöltekin, A., 2015. Applications of 3D City Models: State of the Art Review. ISPRS International Journal of Geo-Information, 4(4), pp. 2842-2889.

Bundesverband Solarwirtschaft, 2014. Statistische Zahlen der deutschen Solarstrombranche (Photovoltaik) (Statistic figures of the German solar power industry (photovoltaic)). URL: https://www.solarwirtschaft.de/fileadmin/media/pdf/2013_2_BS W_Solar_Faktenblatt_Photovoltaik.pdf (09. Jul 2016)

Catalina, T., Iordache, V., Caracaleanu, B., 2013. Multiple regression model for fast prediction of the heating energy demand, Energy and Buildings 57, 302-312.

Catita, C., Redweik, P., Pereire, J., Brito, M. C., 2014. Extending solar potential analysis in buildings to vertical facades. Computers \& Geosciences 66, pp. 1-12.

Cheng, V., Steemers, K., Montavon, M., Compagnon, R., 2006. Urban Form, Density and Solar Potential. PLEA2006 - The 23rd Conference on Passive and Low Energy Architecture, Geneva, Switzerland, 6-8 September 2006

Eicker, U., Nouvel, R., Duminil, E., Coors V., 2014. Assessing passive and active solar energy resources in cities using 3D city models. Energy Procedia 57, pp. 896-905.

European Parliament (2010). Directive 2010/31/EU of the European Parliament and the Council of 19 May 2010 on the energy performance of buildings (recast). URL: http://eurlex.europa.eu/legal-

content/EN/TXT/PDF/?uri=CELEX:32010L0031\&from=en.

Freitas, S., Catita, C. Redweik, P., Brito M.C., 2015. Modelling solar potential in the urban environment: State-of-the-art review. Renewable and Sustainable Energy Reviews 41, pp. 915-931.

Gadsdena, S., Rylatt, M., Lomas, K., 2003. Putting solar energy on the urban map: a new GIS-based approach for dwellings. Solar Energy 74(5), pp. 397-407.

Gassel, A., 1997. Beiträge zur Berechnung solarthermischer und exergieeffizienter Energiesysteme. PhD thesis at the Technische Universität Dresden. 
German Weather Service, 2016. Deutscher Wetter Dienst. Solar radiation $\quad-\quad$ solar energy URL: http://www.dwd.de/EN/ourservices/solarenergy/solarenergie.ht ml. (09. Jul 2016)

Ghassoun, Y., Ruths, M., Löwner, M.-O., Weber, S., 2015. Intra-urban variation of ultrafine particles as evaluated by process related land use and pollutant driven regression modelling. Science of The Total Environment 536, pp. 150-160.

Gröger, G., Kolbe, T. H., Nagel, C., Häfele, K.H., 2012. OpenGIS ${ }^{\circledR}$ City Geography Markup Language (CityGML) Encoding Standard, Version 2.0.0, OGC 08-007r2.

Hofierka, J., Zlocha, M., 2012. A New 3-D Solar Radiation Model for 3-D City Models, Transactions in GIS, 2012, 16(5), pp. 681-690.

Jacubiec, J.A. and Reihard, C. F., 2013. A method for predicting city-wide electricity gains from photovoltaic panels based on LiDAR and GIS data combined. Solar Energy 93, pp. 127-143.

Jaugsch, F., Raile, P., Löwner, M.-O., 2014. Modellierung potenzieller Planflächen für Windkraftanlagen in Bezug auf Lichtemissionen in Niedersachsen. In: Seyfert, E.; Gülch, E.; Heipke, C.; Schiewe, J.; Sester, M. (eds.): Geoinformationen öffnen das Tor zur Welt, 34. Wissenschaftlich-Technische Jahrestagung der DGPF, 26.-28.03.2014, DGPF-Tagungsband 23, Hamburg.

Löwner, M.-O., Benner, J., Gröger, G. \& Häfele, K.H., 2013: New Concepts for Structuring 3D City models - an extended Level of Detail concept for CityGML Buildings. - Murgante, B. et al. (eds.): 13th International Conference on Computational Science and Its Applications, Part III, LNCS 7973: 466-480, Springer, Berlin.

Lu L., Becker, T., Löwner, M.-O., in press. 3D Complete Traffic Noise Analysis Based on CityGML. Lecture Notes in Geoinformation and Cartography, 2016.

Lukač, N., Žlaus, D. Seme, S., Žalik, B., Štumberger, G., 2013. Rating of roofs' surfaces regarding their solar potential and suitability for PV systems, based on LiDAR data. Applied Energy 102, pp. 803-812.

Meeus, J., 2000. Astronomical Algorithms, Willmann-Bell, Richmond.

Nguyen, H., Pearce, J.M., 2012. Incorporating shading losses in solar photovoltaic potential assessment at the municipal scale. Sol. Energy 86 (5), pp. 1245-1260.

Palz, W. and Greif, J., 1996. European Solar Radiation Atlas: Solar Radiation on Horizontal and Inclined Surfaces, 3rd Improved and Revised Edition. Springer, Berlin.

Redweik, P., Catita, C., Brito, M., 2013. Solar energy potential on roofs and façades in an urban landscape. Solar Energy, 97(5), pp 332-341.

Richter, M. and Löwner, M.-O., 2011. Risikobewertung von Sichtbehinderungen durch niedrige Sonnenstände für das Verkehrswegenetz. (Risk assessment of dazzling by the sun for the street network) In: Schwering, A.; Pebesma, E., Behncke, K. (eds.): Geoinformatik 2011 "Geochange", ifgiPrints 41, pp. 223227.
Scartezzini, J.-L., Montavon, M., Compagnon, R., 2002. Computer Evaluation of the Solar Energy Potential in an Urban Environment. EuroSun 2002, Bologna.

Š́ri, M. and Hofierka, J. 2004. A new GIS-based solar radiation model and its application to photovoltaic assessments. Transactions in GIS 8, pp. 175-90.

Wieland, M., Nichersu, A., Murshed, S.M., Wendel, J., 2015. Computing solar radiation on CityGML Building data. AGILE 2015.

Wittmann, H., Bajons, P., Doneus, M., Friesinger, H., 1997. Identification of roof areas suited for solar energy conversion systems. Renewable Energy 11(1), pp. 25-36.

Revised June 2016 